\section{SAT0372 INCREASED CAROTID INTIMA-MEDIA THICKNESS IN HYPERURICEMIC INDIVIDUALS MAY BE EXPLAINED BY HYPERHOMOCYSTEINEMIA ASSOCIATED WITH RENAL DYSFUNCTION}

S. Choi ${ }^{1}$, J.H. Park' ${ }^{1}$, J.-S. Song ${ }^{1}$, E.-J. Kang ${ }^{2}$, K.-H. Lee ${ }^{3} .{ }^{1}$ Internal Medicine, Chung-Ang University College of Medicine, Seoul; ${ }^{2}$ Internal Medicine, Busan Medical Center, Busan; ${ }^{3}$ Internal Medicine, Dongguk University College of Medicine, Goyang, Korea, Republic Of

Background: Both hyperuricemia and hyperhomocysteinemia are known to be associated with the deterioration of vascular endothelial function and are regarded as important risk factors for atherosclerotic vascular diseases. However, there has been no report about the relationship between homocysteine (Hcy) and atherosclerosis in patients with hyperuricemia.

Objectives: In this study, we evaluated the relationship between the carotid IMT and various clinical parameters including renal function and serum Hcy level in patients with hyperuricemia, and investigated the possible mechanism of how hyperuricemia is related with the increase of carotid IMT.

Methods: A total of 1228 subjects who visited the health promotion centre of hospital were enrolled in this study. All subjects completed both carotid ultrasonography and laboratory measurement, including serum Hcy levels and renal function. Serum Hcy levels were measured by a competitive immunoassay using direct chemiluminescent. Carotid IMT was evaluated by B-mode carotid ultrasonography.

Results: Hyperuricemic patients showed higher carotid IMT values compared with normouricemic patients $(1.12 \pm 0.64 \mathrm{~mm}$ vs. $1.02 \pm 0.50 \mathrm{~mm}, \mathrm{p}=0.043)$. The serum Hcy levels were significantly higher in the hyperuricemic group than in the normouricemic group $(13.39 \pm 4.42 \mu \mathrm{mol} / \mathrm{L}$ vs. $11.69 \pm 3.65 \mu \mathrm{mol} / \mathrm{L}, \mathrm{p}<0.001)$. In patients with hyperuricemia, serum uric acid levels were negatively correlated with estimated glomerular filtration rates (eGFR) $(\gamma=-0.334, p<0.001)$, and eGFR were negatively correlated with serum Hcy levels $(; \gamma=-0.490, p<0.001)$. Carotid IMT was correlated with serum Hcy levels $(\gamma=0.196, p=0.008)$, and atherosclerotic changes of carotid artery measured by carotid ultrasonography increased 1.09fold (OR, 95\% Cl 1.006-1.185, $p=0.036)$ per $1 \mu \mathrm{mol} / \mathrm{L}$ difference in serum homocysteine levels. In multivariate linear regression analysis, carotid IMT was affected by reduced eGFR $(\beta=-0.263, p=0.002)$.

Conclusions: Carotid IMT was higher in patients with hyperuricemia than in normouricemic individuals. This study suggests that impairment of the renal function in patients with hyperuricemia may induce the increase in carotid IMT via increased serum Hcy levels.

Disclosure of Interest: None declared

DOI: 10.1136/annrheumdis-2018-eular.6274

\section{SAT0373 \\ PREVENTING A LARGE MAJORITY OF INCIDENT GOUT CASES BY MODIFYING KEY RISK FACTORS: FINDINGS FROM A PROSPECTIVE COHORT OF 44,629 MEN OVER 26 YEARS}

S.K. Rai ${ }^{1,2,3}$, N. Lu ${ }^{3}$, C. Yokose ${ }^{1}$, H.K. Choi ${ }^{1,3} .{ }^{1}$ Division of Rheumatology, Allergy, Immunology, Massachusetts General Hospital, Harvard Medical School; ${ }^{2}$ Department of Nutrition, Harvard T.H. Chan School of Public Health; ${ }^{3}$ Channing Division of Network Medicine, Department of Medicine, Brigham and Women's Hospital, Harvard Medical School, Boston, USA

Background: Many modifiable risk factors have been found to be independently associated with the risk of developing gout, including dietary factors (e.g., intakes of red meat and fructose), adiposity, alcohol intake, and diuretic use. Conversely, healthy dietary patterns (e.g., Dietary Approaches to Stop Hypertension [DASH]) and a high intake of vitamin $\mathrm{C}$ have been shown to be independently associated with lower gout risk. However, the potential combined impact of these factors on the risk of developing gout is unknown.

Objectives: We aimed to estimate the proportion of incident gout cases that could theoretically be avoided through the simultaneous adoption of multiple low-risk behaviours, including low body mass index (BMI), consumption of a DASH-style eating pattern, no alcohol intake, vitamin $C$ supplementation, and no diuretic use. Methods: From 1986 to 2012, we prospectively followed 44629 men free from gout at baseline in the Health Professionals Follow-up Study. Lifestyle, anthropometric, and medical information was collected at baseline and updated biennially. Dietary data were obtained using validated food frequency questionnaires at baseline and approximately every 4 years during follow-up. We ascertained incident cases of gout using the American College of Rheumatology survey criteria for gout. We defined low-risk groups according to combinations of the following five factors: a low BMI $\left(<25 \mathrm{~kg} / \mathrm{m}^{2}\right)$, adherence to a DASH-style diet, no alcohol intake, vitamin C supplementation ( $>1500 \mathrm{mg}$ ), and no diuretic use. Cox proportional hazard regression models were used to estimate the association of each risk factor with the development of gout and calculate the population attributable risk percent (PAR\%).

Results: During 950086 person-years of follow-up, incident gout developed in 1687 participants. All five modifiable risk factors were independently associated with incident gout. Obesity was the single most important predictor of gout; al other risk factors were also associated with a statistically significant increased risk of gout, even after adjustment for BMI. As compared with the rest of the cohort, men in the low-risk group (comprised of all five low-risk factors; $4.4 \%$ of men) had a relative risk of gout of 0.30 (95\% confidence interval [Cl], 0.12 to 0.72 ) (table 1 ) Accordingly, the PAR\% for all five risk factors combined was $70 \%$ (table 1). The PAR\% for four and three risk factors was $64 \%$ and $50 \%$, respectively (table 1 ).

Abstract SAT0373 - Table 1. Relative and Population Attributable Risks of Gout for Groups Defined by Combinations of Modifiable Risk Factors

\begin{tabular}{|c|c|c|c|c|}
\hline & $\begin{array}{l}\text { Percentage } \\
\text { of Men } \\
(\%)\end{array}$ & $\begin{array}{l}\text { Number of } \\
\text { Gout Cases }\end{array}$ & $\begin{array}{c}\text { Relative Risk } \\
\text { (95\% CI) }\end{array}$ & PAR\% \\
\hline $\begin{array}{l}3 \text { factors in low- } \\
\text { risk category a }\end{array}$ & 11.0 & 24 & $\begin{array}{c}0.49(0.33, \\
0.74)\end{array}$ & 50 \\
\hline $\begin{array}{l}4 \text { factors in low- } \\
\text { risk category b }\end{array}$ & 10.3 & 15 & $\begin{array}{c}0.35(0.21, \\
0.59)\end{array}$ & 64 \\
\hline $\begin{array}{l}5 \text { factors in low- } \\
\text { risk category c }\end{array}$ & 4.4 & 5 & $\begin{array}{c}0.30(0.12 \\
0.72)\end{array}$ & 70 \\
\hline \multicolumn{5}{|c|}{$\begin{array}{l}\text { Abbreviations: BMI, body mass index. CI, confidence interval. DASH, Dietary Approaches to Stop } \\
\text { Hypertension. PAR\%, Population attributable risk percent. } \\
\text { Relative risks were adjusted for total energy intake, coffee intake, and histories of renal failure and } \\
\text { hypertension. } \\
\text { 'LowBMI, highest quintile of DASH diet score, and no alcohol intake. } \\
\text { 'Low BMI, highest quintile of DASH diet score, no alcohol intake, and no diuretic use. } \\
\text { 'LowBM, highest quintile of DASH diet score, no alcohol intake, no diuretic use, and vitamin C } \\
\text { supplementation. }\end{array}$} \\
\hline
\end{tabular}

Conclusions: Five modifiable risk factors accounted for $70 \%$ of incident gout cases in this large prospective cohort of male health professionals. Assuming a causal relation, our findings support the hypothesis that the vast majority of cases of gout could be prevented by modifying key risk factors.

Acknowledgements: This study was supported by a grant from the National Institutes of Health (R01AR065944)

Disclosure of Interest: None declared

DOI: 10.1136/annrheumdis-2018-eular.6942

\section{SAT0374 LESINURAD (LESU) ADJUNCTIVE THERAPY WITH ALLOPURINOL (ALLO) IN PATIENTS NOT RESPONDING TO ALLO MONOTHERAPY: POOLED POST HOC SAFETY AND EFFICACY ANALYSIS IN A PATIENT SUBGROUP USING CONCOMITANT DIURETICS AT BASELINE (BL)}

T. Bardin ${ }^{1}$, R.G. Karra ${ }^{2}$, A. So ${ }^{3}$, A.-K. Tausche ${ }^{4}$, I. Wild², H. Hagedorn ${ }^{2}$ P. Kandaswamy ${ }^{2}$, F. Perez-Ruiz ${ }^{5} .{ }^{1}$ Rheumatology, Hôpital Laribroisière, Paris, France; ${ }^{2}$ Grunenthal GmbH, Aachen, Germany; ${ }^{3}$ Rheumatology, chuv, Lausanne, Switzerland; ${ }^{4}$ University Clinic, Dresden, Germany; ${ }^{5}$ Rheumatology, University of the Basque Country, Biscai, Spain

Background: LESU is approved as adjunctive therapy in combination with xanthine oxidase inhibitors (XOI) for gout PT not responding to XOI alone ${ }^{1}$. Gout PT often have hypertension (HT) for which diuretics especially thiazide and thiazidelike diuretics (TTLD) are prescribed. TTLD contributes to hyperuricemia ${ }^{2}$ by acting on OAT4 transporter, which is inhibited by LESU.

Objectives: To assess the efficacy and safety of LESU+ALLO in the subgroup of PT using concomitant diuretics at BL in CLEAR 1 and CLEAR 2, two randomised double-blind, placebo-controlled Phase 3 studies that evaluated LESU200/ $400 \mathrm{mg}$ daily in combination with ALLO vs ALLO + placebo. ${ }^{3 \& 4}$.

Methods: Data from both trials of 1,213 PT, was pooled and PT group using diuretics at baseline was compared to non-users with respect to SUA target and TEAE.

Results: Totally 221 PT received diuretics, $>90 \%$ due to $\mathrm{HT}$ and $\sim 80 \%$ being TTLD. In both groups, LESU +ALLO doubled the number of PT reaching sUA tar get of $<6.0 \mathrm{mg} / \mathrm{dL}$ vs ALLO +PBO at month $6(\mathrm{~m}-6)$ and $12(\mathrm{~m}-12)$ (table 1$)$. At m12 , the response rate in PT receiving TTLD was $60.8 \%, 61.5 \%$ in the LESU 200 and $400 \mathrm{mg}$ group, and $26.6 \%$ in the ALLO alone group, and $47.5 \%, 50.5 \%$, and $25.7 \%$ in PT not receiving TTLD respectively. The safety profile was comparable 
except for transient and reversible serum creatinine elevations in the LESU groups. (table 1).

Abstract SAT0374 - Table 1

\begin{tabular}{|c|c|c|c|c|c|c|}
\hline \multirow[t]{2}{*}{ Variable } & \multicolumn{3}{|c|}{ Group receiving Diuretics } & \multicolumn{3}{|c|}{ Group not receiving Diuretics } \\
\hline & $\begin{array}{l}\text { PBO } \\
+\mathrm{ALLO} \\
{[\mathrm{n}=64]}\end{array}$ & $\begin{array}{c}\text { LESU } \\
200 \mathrm{mg} \\
+\mathrm{ALLO} \\
{[\mathrm{n}=79]}\end{array}$ & $\begin{array}{c}\text { LESU } \\
400 \mathrm{mg} \\
+\mathrm{ALLO} \\
{[\mathrm{n}=78]}\end{array}$ & $\begin{array}{c}\text { PBO } \\
+ \text { ALLO } \\
{[n=343]}\end{array}$ & $\begin{array}{c}\text { LESU } \\
200 \mathrm{mg} \\
+\mathrm{ALLO} \\
{[\mathrm{n}=326]}\end{array}$ & $\begin{array}{c}\text { LESU } \\
400 \mathrm{mg} \\
+\mathrm{ALLO} \\
{[\mathrm{n}=323]}\end{array}$ \\
\hline \multicolumn{7}{|c|}{ Efficacy, proportion of PT achieving [number (\%)]: } \\
\hline $\begin{array}{l}\mathrm{sUA}<6.0 \mathrm{mg} / \\
\mathrm{dL} \text { at } \mathrm{m}-6\end{array}$ & $\begin{array}{c}19 \\
(29.7)\end{array}$ & $48(60.8) \dagger$ & $57(73.1)^{*}$ & $85(24.8)$ & $174(53.4)^{*}$ & $195(60.4)^{*}$ \\
\hline $\begin{array}{l}\mathrm{sUA}<6.0 \mathrm{mg} / \\
\mathrm{dL} \text { at } \mathrm{m}-12\end{array}$ & $\begin{array}{c}17 \\
(26.6)\end{array}$ & $48(60.8)^{*}$ & $48(61.5)^{\star}$ & $88(25.7)$ & $155(47.5)^{*}$ & $163(50.5)^{\star}$ \\
\hline \multicolumn{7}{|c|}{ Safety, proportion of PT reporting [number (\%)]: } \\
\hline Any TEAEs & $\begin{array}{c}45 \\
(70.3)\end{array}$ & $62(78.5)$ & $65(83.3)$ & $\begin{array}{c}239 \\
(69.7)\end{array}$ & $237(72.7)$ & $252(78.0)$ \\
\hline $\begin{array}{l}\leftarrow \text { Serum } \\
\text { creatinine } \\
\text { by } \geq 1.5\end{array}$ & $2(3.1)$ & $2(2.5)$ & $11(14.1)$ & $5(1.5)$ & $17(5.2)$ & $47(14.6)$ \\
\hline
\end{tabular}

Conclusions: LESU +ALLO doubled the number of PT reaching SUA target of $<6.0 \mathrm{mg} / \mathrm{dL}$ at $\mathrm{m}-6$ and sustained at $\mathrm{m}-12$, irrespective of TTLD use. Adjunctive therapy with LESU +ALLO is safe and efficacious even in PT subgroups using concomitant TTLD.

\section{REFERENCES:}

[1] Zurampic ${ }^{\circledR}$ (lesinurad) SmPC. Grünenthal GmbH, February 2016.

[2] Bruderer S, et al. Arthritis Rheumatol 2014 Jan;66(1):185-96.

[3] Saag KG, et al. Arthritis Rheumatol 2017;69:203-12.

[4] Bardin T, et al. Ann Rheum Dis 2017;76:811-20.

Disclosure of Interest: T. Bardin Grant/research support from: Astrazeneca, Ipsen, Menarini, Consultant for: Grunenthal, Speakers bureau: Astrazeneca, Ipsen, Menarini, Grunenthal, Novartis, R. Karra Employee of: Grunenthal, A. So Consultant for: Grunnenthal, Sobi, A.-K. Tausche Consultant for: Berlin-Chemie, Menarini, Ipsen, Sobi, Novartis, Ardea Biosciences/AstraZeneca, I. Wild Employee of: Grunenthal, H. Hagedorn Employee of: Grunenthal, P. Kandaswamy Employee of: Grunenthal, F. Perez-Ruiz Consultant for: Grünenthal, Menarini, Spanish Society of Rheumatology, Cruces Hospital Rheumatology Association.

DOI: 10.1136/annrheumdis-2018-eular.2812

\section{SAT0375 IMPACT OF FEBUXOSTAT ON RENAL FUNCTION AMONG GOUT PATIENTS WITH DIFFERENT RENAL FUNCTION}

T.-T. Chung ${ }^{1}$, C.-F. Kuo ${ }^{1,2}$, J.-S. Chen ${ }^{1}$, M.-J. Chiou ${ }^{1} .{ }^{1}$ Division of Rheumatology, Allergy and Immunology, Chang Gung Memorial Hospital, Taoyuan, Taiwan, Province of China; ${ }^{2}$ Division of Rheumatology, Orthopaedics and Dermatology, University of Nottingham, Nottingham, UK

Background: Febuxostat is a new xanthine oxidase inhibitor which is effective in the treatment of hyperuricemia. Its use in people with different levels of renal function has not been thoroughly assessed.

Objectives: To assess the risk of renal function deterioration in gout patients using febuxostat and compare it with patients using allopurinol and other uricosuric agents.

Methods: We included 5882 adult patients with gout diagnosed between 2012 and 2015. We divided patients into three groups by usage of urate-lowering drugs used (allopurinol, febuxostat and uricosuric agents including benzbromarone, probenecid and sulfinpyrazone). The primary outcome was a progress of one chronic kidney disease (CKD) stage. The index date was the first date of urate-lowering drugs used. We follow each patient to the date of event, death, switch to other drug or the end of the study. The Cox proportional hazards model was used to estimate the adjusted hazard ratios (HRs), adjusted for age, sex, baseline eGFR, baseline serum urine acid, comorbidity, co-medication.

Results: The incident rate of the renal function deterioration was $2.37(95 \% \mathrm{Cl}$, 1.75-3.14) per 1000 person-days in allopurinol users, $1.54(95 \% \mathrm{Cl}, 1.30-1.81)$ per 1000 person-days in febuxostat users and $1.43(95 \% \mathrm{Cl}, 1.32-1.56)$ per 1000 person-days in uricosuric agent users. The HRs of progession of CKD stage in febuxostat and uricosuric agent users were $0.98(95 \% \mathrm{Cl}, 0.70-1.38)$ and 0.80 (95\% Cl, 0.59-1.09) compared with allopurinol. Among febuxostat users, the HRs were $1.80(95 \% \mathrm{Cl}, 0.85-3.98)$ in patients with an estimated glomerular filtration rate $\left.(\mathrm{eGFR}) \geq 90 \mathrm{ml} / \mathrm{min} / 1.73 \mathrm{~m}^{2}\right), 1.06(95 \% \mathrm{Cl}, 0.56-2.03)$ for patients with an
eGFR $60-89 \mathrm{ml} / \mathrm{min} / 1.73 \mathrm{~m}^{2}, 0.78(95 \% \mathrm{Cl}, 0.45-1.42)$ for patients with an eGFR $30-59 \mathrm{ml} / \mathrm{min} / 1.73 \mathrm{~m}^{2}$ and $0.73(95 \% \mathrm{Cl}, 0.22-3.52)$ for patients with an eGFR $15-29 \mathrm{ml} / \mathrm{min} / 1.73 \mathrm{~m}^{2}$. Among uricosutic agent users, the HRs were $0.94(95 \%$ $\mathrm{Cl}, 0.52-1.88)$ in patients with an eGFR $\geq 90 \mathrm{ml} / \mathrm{min} / 1.73 \mathrm{~m}^{2}, 0.88(95 \% \mathrm{Cl}, 0.55$ $1.50)$ in patients with an eGFR $60-89 \mathrm{ml} / \mathrm{min} / 1.73 \mathrm{~m}^{2}, 0.71(95 \% \mathrm{Cl}, 0.41-1.28)$ in patients with an eGFR $30-59 \mathrm{ml} / \mathrm{min} / 1.73 \mathrm{~m}^{2}$ and $0.71(95 \% \mathrm{Cl}, 0.19-3.62)$ in patients with an eGFR $15-29 \mathrm{ml} / \mathrm{min} / 1.73 \mathrm{~m}^{2}$.

Conclusions: Renal function deterioration is not uncommon after initiation of urate-lowering treatment and febuxostat has a similar renal safety profile as allopurinols and uricosuric agents.

Disclosure of Interest: None declared

DOI: 10.1136/annrheumdis-2018-eular.6882

\section{SAT0376 THE INCIDENCE, PREVALENCE AND USE OF URATE LOWERING AGENTS IN HONG KONG: A POPULATION STUDY FROM 2006 TO 2016}

T.T. Cheung ${ }^{1}$, M.F. Tsoi ${ }^{1}$, M.H. Chung ${ }^{2}$, B.M.Y. Cheung ${ }^{1}$, W.C.S. Lau ${ }^{1} .{ }^{1}$ Medicine, The University of Hong Kong; ${ }^{2}$ Medicine, Queen Mary Hospital, Hong Kong, Hong Kong

Background: The prevalence of gout has increased significantly over the past decade, espeically in developed countries and Oceanic populations. The estimated prevalence of gout in the US, Canada and European countries was $3 \%$. Asian countries, except Taiwan, were considered to have a lower prevalence of gout due to differences in ethnicity and lifestyle.

Since there are no recent epidemiological data on gout in Hong Kong, we conducted this population study to determine the incidence and prevalence of gout in Hong Kong as well as the utilisation of urate lowering agents among patients with gout.

Objectives: To determine the incidence, prevalence of gout and use of urate lowering agents in Hong Kong

Methods: Data were retrieved from the Clinical Data Analysis and Reporting System (CDARS) of the Hospital Authority. The Hospital Authority is the only public healthcare provider in Hong Kong. Since treatment is heavily subsidised and available to all residents, it covers more than $90 \%$ of all medical care for the general population in Hong Kong.

Clinical data including demographic, diagnosis of gout, serum urate levels and prescriptions of urate lowering agents were retrieved from CDARS from 2006 to 2016. For inclusion, subjects must have attended any out-patient clinics or accident and emergency department (with or without hospitalisation) in 2005. Subjects with a diagnosis of gout who died before 2006 were excluded. All subjects were followed until the cut-off date or death.

Gout was defined as the physician diagnosis and coding in CDARS. The serum urate levels achieved after prescribing urate lowering agents were the means of all serum urate levels 6 months after prescriptions.

Results were analysed by $\mathrm{R}$ statistics version 3.3.3. with package 'prevalence' version 0.4.0.

Results: 2741862 participants were included in the analysis. Both the incidence and prevalence of gout in Hong Kong have increased over the past 10 years. In 2016 , the crude and age-standardised prevalence of gout were $2.92 \%$ and $1.44 \%$, respectively. $6.26 \%$ of the general populaton aged 80 years or older was diagnosed to have gout.

Despite the increase in incidence and prevalence of gout in Hong Kong, the utilisation of urate lowering agents remained low. in 2016 , only $25.55 \%$ of patients with gout were prescribed urate lowering agents. More importantly, only $35.8 \%$ of those could achieve the therapeutic target of serum urate level $<6 \mathrm{mg} / \mathrm{dL}$.
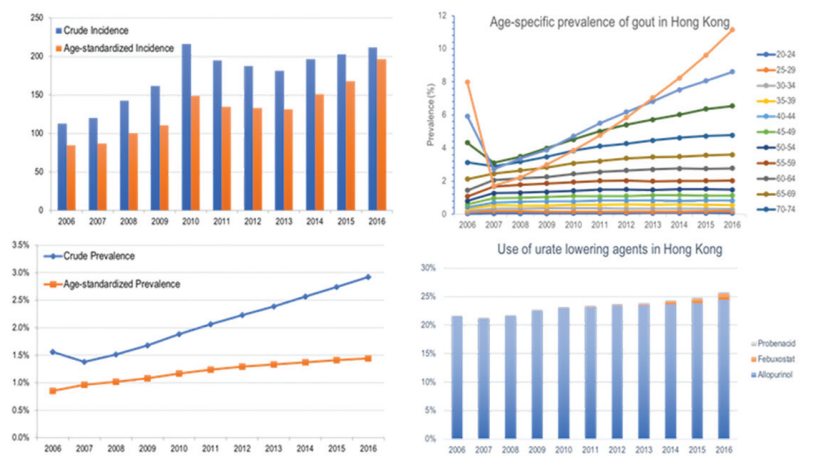

Conclusions: Population ageing has led to increases in incidence and prevalence of gout in Hong Kong. In 2016, the crude prevalence of gout in Hong Kong was $2.92 \%$, which is similar to figures reported in western countries. Despite an 